\title{
Assessing the impact of different sources of topographic data on 1-D hydraulic modelling of floods
}

\author{
A. Md Ali ${ }^{1,2}$, D. P. Solomatine ${ }^{1,3}$, and G. Di Baldassarre ${ }^{4}$ \\ ${ }^{1}$ Department of Integrated Water System and Knowledge Management, UNESCO-IHE Institute for Water Education, \\ Delft, the Netherlands \\ ${ }^{2}$ Department of Irrigation and Drainage, Kuala Lumpur, Malaysia \\ ${ }^{3}$ Water Resource Section, Delft University of Technology, the Netherlands \\ ${ }^{4}$ Department of Earth Sciences, Uppsala University, Sweden \\ Correspondence to: A. Md Ali (a.ali@unesco-ihe.org)
}

Received: 14 May 2014 - Published in Hydrol. Earth Syst. Sci. Discuss.: 3 July 2014

Revised: 16 December 2014 - Accepted: 4 January 2015 - Published: 30 January 2015

\begin{abstract}
Topographic data, such as digital elevation models (DEMs), are essential input in flood inundation modelling. DEMs can be derived from several sources either through remote sensing techniques (spaceborne or airborne imagery) or from traditional methods (ground survey). The Advanced Spaceborne Thermal Emission and Reflection Radiometer (ASTER), the Shuttle Radar Topography Mission (SRTM), the light detection and ranging (lidar), and topographic contour maps are some of the most commonly used sources of data for DEMs. These DEMs are characterized by different precision and accuracy. On the one hand, the spatial resolution of low-cost DEMs from satellite imagery, such as ASTER and SRTM, is rather coarse (around 30 to $90 \mathrm{~m}$ ). On the other hand, the lidar technique is able to produce high-resolution DEMs (at around $1 \mathrm{~m}$ ), but at a much higher cost. Lastly, contour mapping based on ground survey is time consuming, particularly for higher scales, and may not be possible for some remote areas. The use of these different sources of DEM obviously affects the results of flood inundation models. This paper shows and compares a number of 1-D hydraulic models developed using HEC-RAS as model code and the aforementioned sources of DEM as geometric input. To test model selection, the outcomes of the 1-D models were also compared, in terms of flood water levels, to the results of 2-D models (LISFLOOD-FP). The study was carried out on a reach of the Johor River, in Malaysia. The effect of the different sources of DEMs (and different resolutions) was investigated by considering the performance of the hydraulic models in simulating flood water levels as well
\end{abstract}

as inundation maps. The outcomes of our study show that the use of different DEMs has serious implications to the results of hydraulic models. The outcomes also indicate that the loss of model accuracy due to re-sampling the highest resolution DEM (i.e. lidar $1 \mathrm{~m}$ ) to lower resolution is much less than the loss of model accuracy due to the use of lowcost DEM that have not only a lower resolution, but also a lower quality. Lastly, to better explore the sensitivity of the 1-D hydraulic models to different DEMs, we performed an uncertainty analysis based on the GLUE methodology.

\section{Introduction}

In hydraulic modelling of floods, one of the most fundamental input data is the geometric description of the floodplains and river channels often provided in the form of digital elevation models (DEMs). During the past decades, there has been a significant change in data collection for topographic mapping techniques, from conventional ground survey to remote sensing techniques (i.e. radar wave and laser altimetry; e.g. Mark and Bates, 2000; Castellarin et al., 2009). This shift has a number of advantages in terms of processing efficiency, cost effectiveness and accuracy (Bates, 2012; Di Baldassarre and Uhlenbrook, 2012).

DEMs can be acquired from many sources of topographic information ranging from the high-resolution and accurate, but costly, lidar (Light Detection and Ranging) obtained from lower altitude, to low-cost, and coarse resolution, spaceborne 
data, such as ASTER (Advanced Spaceborne Thermal Emission and Reflection Radiometer) and SRTM (Shuttle Radar Topography Mission). DEMs can also be developed from traditional ground surveying (e.g. topographic contour maps) by interpolating a number of elevation points.

DEM horizontal resolution, vertical precision and accuracy differ considerably. This diversity is caused by the types of equipment and methods used in obtaining the topographic data. When used as an input to hydraulic modelling, the differences in the quality of each DEM subsequently result in differences in model output performance. In addition, resampling processes of raster data via a geographic information system (GIS) may also deteriorate the accuracy of the DEMs. The usefulness of diverse topographic data in supporting hydraulic modelling of floods is subject to the availability of DEMs, economic factors and geographical conditions of survey area (Cobby and Mason, 1999; Casas et al., 2006; Schumann et al., 2008).

To date, a number of studies have been carried out with the aim of evaluating the impact of accuracy and precision of the topographic data on the results of hydraulic models (e.g. Table 1).

Werner (2001) investigated the effect of varying grid element size on flood extent estimation from a 1-D model approach based on a lidar DEM. The study found that the flood extent estimation increased as the resolution of the DEM becomes coarser.

Horrit and Bates (2001) demonstrated the effects of spatial resolution on a raster-based flood model simulation. Simulation tests were performed at resolution sizes of 10, 20, 50, $100,250,500$ and $1000 \mathrm{~m}$ and the predictions were compared with satellite observations of inundated area and ground measurements of flood-wave travel times. They found that the model reached a maximum performance at resolution of $100 \mathrm{~m}$ when calibrated against the observed inundated area. The resolution of $500 \mathrm{~m}$ proved to be adequate for the prediction of water levels. They also highlighted that the predicted flood-wave travel times are strongly dependent on the model resolution used.

Wilson and Atkinson (2005) set up a 2-D model, LISFLOOD-FP, using three different DEMs - contour data set, synthetic-aperture radar (SAR) data set, and differential global positioning system (DGPS) - used to predict flood inundation for 1998 flood event in the United Kingdom. The results showed that the contour data sets resulted in a substantial difference in the timing and the extent of flood inundation when compared to the DGPS data set. Although the SAR data set also showed differences in the timing and the extent, it was not as massive as for the contour data set. Nevertheless, the authors also highlighted a potential problem with the use of satellite remotely sensed topographic data in flood hazard assessment over small areas.

Casas et al. (2006) investigated the effects of the topographic data sources and resolution on 1-D hydraulic modelling of floods. They found that the contour-based digital ter- rain model (DTM) was the least accurate in the determination of the water level and inundated area of the floodplain; however, the GPS-based DTM led to a more realistic estimate of the water surface elevation and of the flooded area. The lidarbased model produced the most acceptable results in terms of water surface elevation and inundated flooded area compared to the reference data. The authors also pointed out that the different grid sizes used in lidar data have no significant effect on the determination of the water surface elevation. In addition, from an analysis of the time-cost ratio for each DEM used, they concluded that the most cost-effective technique for developing a DEM by means of an acceptable accuracy is from laser altimetry survey (lidar), especially for large areas.

Schumann et al. (2008) demonstrated the effects of DEMs on deriving the water stage and inundation area. Three DEMs at three different resolutions from three sources (lidar, contour and SRTM DEM) were used for a study area in Luxembourg. By using the HEC-RAS 1-D hydraulic model to simulate the flood propagation, the result shows that the lidar DEM derived water stages by displaying the lowest RMSE, followed by the contour DEM and lastly the SRTM. Considering the performance of the SRTM (it was relatively good with RMSE of $1.07 \mathrm{~m}$ ), they suggested that the SRTM DEM is a valuable source for initial vital flood information extraction in large, homogeneous floodplains.

For the large flood-prone area, the availability of DEM from the public domain (e.g. ASTER, SRTM) makes it easier to conduct a study. Patro et al. (2009) selected a study area in India and demonstrated the usefulness of using SRTM DEM to derive river cross-section for the use in hydraulic modelling. They found that the calibration and validation results from the hydraulic model performed quite satisfactorily in simulating the river flow. Furthermore, the model performed quite well in simulating the peak flow, which is important in flood modelling. The study by Tarekegn et al. (2010) carried out on a study area in Ethiopia used a DEM which was generated from ASTER image. Integration between remote sensing and GIS technique were needed to construct the floodplain terrain and channel bathymetry. From the results obtained, they concluded that the ASTER DEM is able to simulate the observed flooding pattern and inundated area extents with reasonable accuracy. Nevertheless, they also highlighted the need for advanced GIS processing knowledge when developing a digital representation of the floodplain and channel terrain.

Schumann et al. (2010) demonstrate that near real-time coarse-resolution radar imagery of a particular flood event on the River Po (Italy) combined with SRTM terrain height data leads to a water slope remarkably similar to that derived by combining the radar image with highly accurate airborne laser altimetry. Moreover, they showed that this spaceborne flood wave approximation compares well to a hydraulic model thus allowing the performance of the latter, 
Table 1. Summary of studies assessing the impact of topographic input data on the results of flood inundation models.

\begin{tabular}{|c|c|c|c|c|c|}
\hline Author(s) & $\begin{array}{l}\text { Numerical modelling } \\
\left(1-D^{*} / 1-D 2-D^{* *} / 2-D^{* * *}\right)\end{array}$ & $\begin{array}{l}\text { Calibration }^{+} / \\
\text {validation }^{++} \text {data }\end{array}$ & Source of DEMs & $\begin{array}{l}\text { Type of } \\
\text { assessment }\end{array}$ & Study area \\
\hline $\begin{array}{l}\text { Horrit and Bates } \\
\text { (2001) }\end{array}$ & $\begin{array}{l}\text { LISFLOOD- } \\
\text { FP } * * / N C F S * *^{* *}\end{array}$ & SAR flood imagery $^{+}$ & Lidar & Precision & River Severn, UK \\
\hline Werner (2001) & HEC-RAS* & $\mathrm{n} / \mathrm{a}$ & Laser altimetry data & Precision & River Saar, Germany \\
\hline $\begin{array}{l}\text { Wilson and } \\
\text { Atkinson (2005) }\end{array}$ & LISFLOOD-FP** & $\begin{array}{l}\text { SAR flood } \\
\text { imagery }++\end{array}$ & $\begin{array}{l}\text { InSAR, topography \& } \\
\text { GPS }\end{array}$ & Accuracy & River Nene, UK \\
\hline Casas et al. (2006) & HEC-RAS* & $\mathrm{n} / \mathrm{a}$ & $\begin{array}{l}\text { GPS, bathymetry, li- } \\
\text { dar \& topography }\end{array}$ & $\begin{array}{l}\text { Accuracy \& } \\
\text { precision }\end{array}$ & River Ter, Spain \\
\hline $\begin{array}{l}\text { Schumann et } \\
\text { al. (2008) }\end{array}$ & $\begin{array}{l}\text { REFIX } * * * \& \\
\text { HEC-RAS* }\end{array}$ & $\begin{array}{l}\text { Field data }^{+} / 1-\mathrm{D} \\
\text { model output }^{++}\end{array}$ & $\begin{array}{l}\text { Lidar, SRTM } \\
\text { topography }\end{array}$ & Accuracy & $\begin{array}{l}\text { River Alzette, } \\
\text { Luxembourg }\end{array}$ \\
\hline $\begin{array}{l}\text { Schumann et } \\
\text { al. (2010) }\end{array}$ & HEC-RAS* & $\begin{array}{l}\text { Field data }{ }^{+} / \text {lidar } \\
\text { derived water } \\
\text { levels }\end{array}$ & Lidar \& SRTM & Accuracy & River Po, Italy \\
\hline Yan et al. (2013) & HEC-RAS* & $\begin{array}{l}\text { Field data }{ }^{+} / \mathrm{SAR} \\
\text { flood imagery }\end{array}$ & Lidar \& SRTM & Accuracy & River Po, Italy \\
\hline
\end{tabular}

calibrated on a previous event, to be assessed when applied to an event of different magnitude in near-real time.

Paiva et al. (2011) demonstrated the use of SRTM DEM in a large-scale hydrologic model with a full 1-D hydrodynamic module to calculate flow propagation on a complex river network. The study was conducted on one of the major tributaries of the Amazon, the Purus River basin. They found that a model validation using discharge and water level data is capable of reproducing the main hydrological features of the Purus River basin. Furthermore, realistic floodplain inundation maps were derived from the results of the model. The authors concluded that it is possible to employ full hydrodynamic models within large-scale hydrological models even when using limited data for river geometry and floodplain characterization.

Moya Quiroga et al. (2013) used Monte Carlo simulation sampling SRTM DEM elevation, and found a considerable influence of the SRTM uncertainty on the inundation area (the HEC-RAS hydraulic model of the Timis-Bega Basin in Romania was employed).

Most recently, Yan et al. (2013) made a comparison between a hydraulic model based on lidar and SRTM DEM. Besides the DEM inaccuracy, they also introduced uncertainty analysis by considering parameter and inflow uncertainty. The results of this study showed that the differences between the lidar-based model and the SRTM-based model are significant, but within the accuracy that is typically associated with large-scale flood studies.

Yet, the aforementioned studies explored the impact of topographic input data on the results flood inundation models by considering either the accuracy (or quality) or the precision (or resolution) of the DEMs (Table 1). When both accuracy and precision were considered (Casas, 2006), model results were not compared to observations via calibration and validation exercises.

This paper continues the presented line of research and deals with the assessment of the effects of using different DEM data source and resolution in a 1-D hydraulic modelling of floods. The novelty of our study is that both accuracy and precision of the DEM are explicitly considered and their impacts on hydraulic model results is evaluated in terms of both water surface elevation and inundation area. Furthermore, we compare model results via independent calibration and validation exercises and by explicitly considering parameter uncertainty and its potential compensation of inaccuracy of topographic data.

Hence, the goal of our paper is not to validate a specific approach for producing flood inundation maps, but rather to contribute to the existing literature with an original approach assessing the impact of topographic input data on hydraulic modelling of floods.

\section{Study area and available data}

\subsection{Study area}

The study area is located within the Johor River basin in the State of Johor, Malaysia. The river basin has a total area of $2690 \mathrm{~km}^{2}$. The test site is a $30 \mathrm{~km}$ reach of the Johor River. The Johor River channel has a bankfull depth between 5 and $8 \mathrm{~m}$ and average slope around $0.03 \%$. The river reach under study is characterized by a stable main channel from 50 to $250 \mathrm{~m}$ wide. The study area consists of agricultural land, residential and commercial areas (see Fig. 1). As reported by Department of Irrigation and Drainage, Malaysia (DID, 2009), this test site has been experiencing some major historical flood events since 1948. The most recent ones happened 
in December 2006 and January 2007 when more than 3000 families were evacuated.

\subsection{Hydraulic modelling}

Flood inundation modelling was carried out by using the model code HEC-RAS, which was developed by the Hydrologic Engineering Center (HEC) of the United States Army Corps of Engineers (USACE, 2010). HEC-RAS is a 1-D model that can simulate both steady and unsteady flow conditions. In this study, all simulations were performed under unsteady flow conditions. To simulate open channel flows, HEC-RAS numerically solves the full 1-D SaintVenant equations. The HEC-RAS model was set up using 32 cross-sections, whose topography is derived by different DEMs (see below). The observed flow hydrograph at an hourly time step was used as upstream boundary condition, while the friction slope was used as downstream boundary condition. The next section reports the different sources of topographic data used to define the geometric input. To develop flood inundation maps, the results were post-processed by using HEC-GeoRAS, an ArcGIS extension.

1-D hydraulic modelling does not properly simulate river hydraulics and floodplain flows. However, while 2-D models tend to schematize better flood inundation processes, they do not necessarily perform better when applied to real-world case studies because, besides model structure, many other sources of uncertainty affect model results (Werner, 2001; Bates et al., 2003; Pappenberger et al., 2005; Merwade et al., 2008; Di Baldassarre et al., 2009, 2010). A number of authors have carried out comparative studies and showed that the performance of 1-D models is often very close to that of 2-D models (e.g. Horrit and Bates, 2002; Castellarin et al., 2009; Cook and Merwade, 2009). Also, 1-D models are typically more efficient than 2-D models from a computation viewpoint, allowing for numerous simulations and uncertainty analysis to be carried out. In our case study, for a given flow, topography, river reach and a number of simulations, a HEC-RAS simulation (excluding post-processing GIS) took only $4 \mathrm{~h}$ to predict inundated area, whereas LISFLOOD-FP took around $26 \mathrm{~h}$.

Anyhow, to properly test our model selection, we carried out a number of additional experiments (see Sect. 4.2) and compared the results of 1-D models to the results obtained with a 2-D model (LISFLOOD-FP; e.g. Hunter et al., 2006; Bates et al., 2010; Neal et al., 2012; Coulthard et al., 2013).

\subsection{Digital elevation model}

The required input data for the HEC-RAS include the geometry of the floodplain and the river, which is provided by a number of cross-sections. We identified several sources of DEM data for our study area (details are given below) with different spatial resolution and accuracy (Fig. 2):
Table 2. Information about the eight digital elevation models used as topographical input.

\begin{tabular}{llr}
\hline Model name & DEM type & Resolution (m) \\
\hline Jhr L1 & lidar & $1 \mathrm{~m}$ \\
Jhr L2 & (rescaled from lidar) & 2 \\
Jhr L20 & (rescaled from lidar) & 20 \\
Jhr L30 & (rescaled from lidar) & 30 \\
Jhr L90 & (rescaled from lidar) & 90 \\
Jhr T20 & Contour maps & 20 \\
Jhr A30 & ASTER & 30 \\
Jhr S90 & SRTM & 90 \\
\hline
\end{tabular}

1. DEMs derived from an original $1 \mathrm{~m}$ lidar data set (obtained from DID).

2. $20 \mathrm{~m}$ resolution DEM generated from the vectorial $1: 25000$ cartography map obtained from DID with a permission of the Department of Survey and Mapping, Malaysia (DSMP).

3. $30 \mathrm{~m}$ resolution DEM derived from the globally and freely available ASTER data retrieved from the United States Geological Survey (USGS, http://earthexplorer. usgs.gov)

4. $90 \mathrm{~m}$ resolution DEM derived from the globally and freely available SRTM data retrieved from a Consortium for Spatial Information (CGIAR-CSI, www.cgiar-csi. org).

To analyse the influence of spatial resolution and separate it out from the impact of different accuracy, four additional DEMs were obtained by rescaling the original lidar DEM ( $1 \mathrm{~m}$ resolution) to the spatial resolutions of the DEMs derived from vectorial cartography $(20 \mathrm{~m})$, ASTER $(30 \mathrm{~m})$ and SRTM $(90 \mathrm{~m}$ ). Hence, a total of eight DEMs were used (see Table 2) to explore the impact of different topographic information on the hydraulic modelling of floods.

Given that the laser/radar waves used in the remote sensing techniques are not capable of penetrating the water surface and capture the river bed elevations, all the DEMs were integrated with river cross-section data derived from traditional ground survey. The ground survey of the river cross-sections within the study area was systematically carried out at about $1000 \mathrm{~m}$ intervals. Then, the flood simulation results across different data sets were compared to evaluate the effects of data spatial resolutions and data source differences.

\section{Methodology}

\subsection{Evaluating DEM quality}

First, the vertical error of each DEM was evaluated through comparison between the topographic data and 164 GPS 


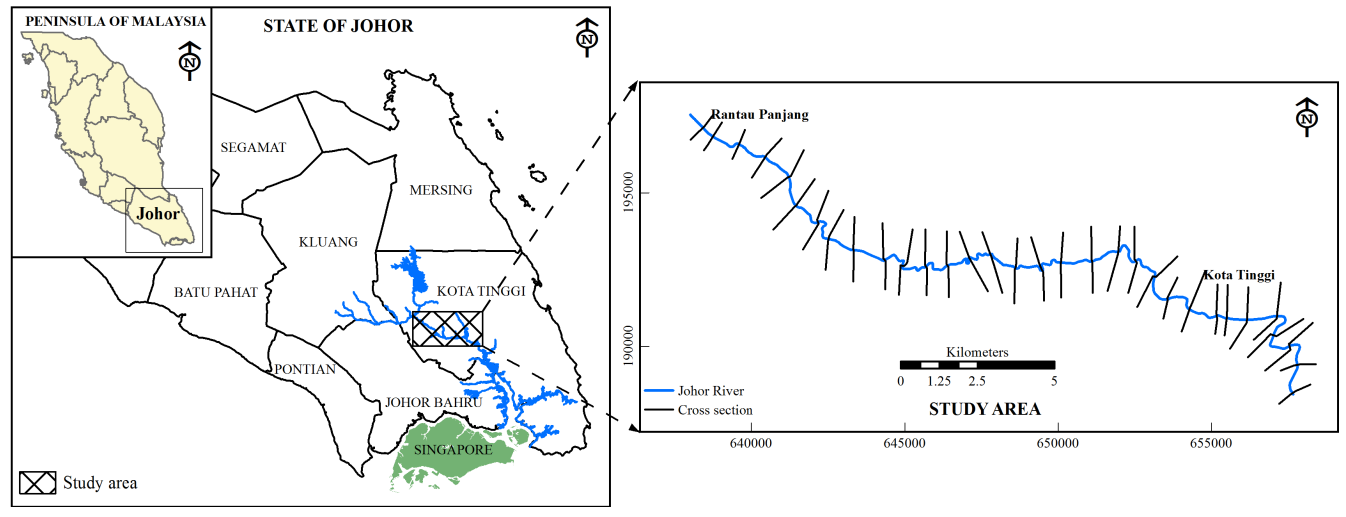

Figure 1. Layout map of study area: Johor River, Malaysia.
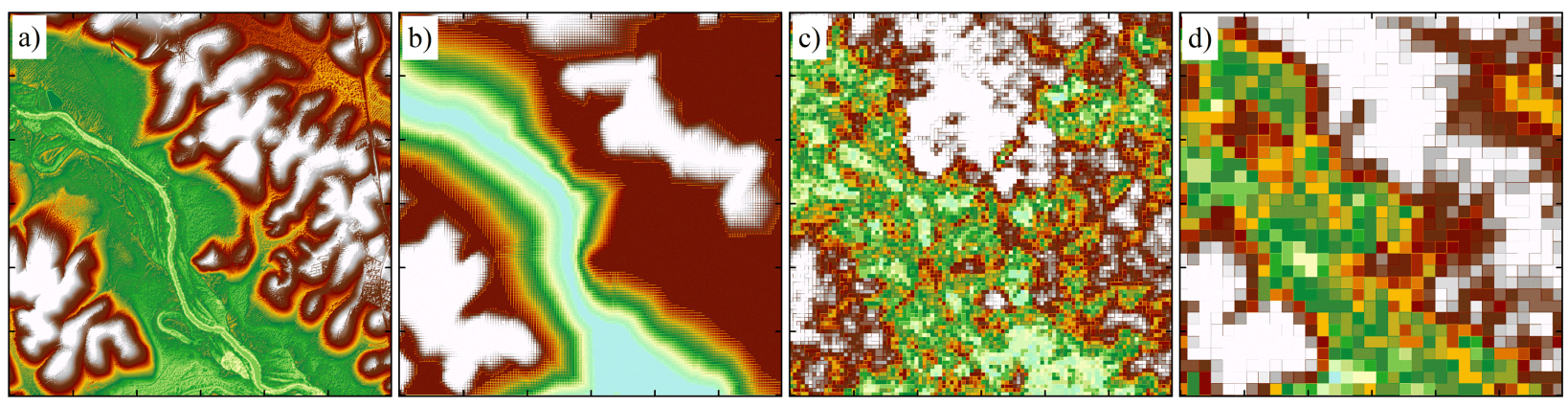

Figure 2. Original DEMs used in this study, based on (a) lidar data, (b) contour map, (c) ASTER data and (d) SRTM data.

ground points taken at random positions within the study area. The value of each reference elevation point was extracted from the study area using GPS survey equipment. The quality of each DEM is assessed by the root mean square error $\left(\mathrm{RMSE}_{\mathrm{DEM}}\right)$ and mean error $\left(\mathrm{ME}_{\mathrm{DEM}}\right)$. Thus

$\mathrm{RMSE}_{\mathrm{DEM}}=\sqrt{\frac{\sum_{i=1}^{n}\left(\operatorname{Elev}_{\mathrm{GPS}}-\operatorname{Elev}_{\mathrm{DEM}}\right)^{2}}{n}}$,

where $\operatorname{Elev}_{\mathrm{GPS}}$ is the reference elevation (m) derived from GPS, Elev $v_{D E M}$ is the corresponding value derived from each DEM, and $n$ corresponds to the total numbers of points.

\subsection{Model calibration and validation}

Then, data from two recent major flood events that occurred along the Johor River in 2006 and 2007 were used for independent calibration and validation of the models. The estimated peak flow of the 2006 event is approximately $375 \mathrm{~m}^{3} \mathrm{~s}^{-1}$, while the one of the 2007 event is around $595 \mathrm{~m}^{3} \mathrm{~s}^{-1}$. Both discharge data were measured and recorded at Rantau Panjang hydrological station. The 2006 flood data were used for the calibration exercise, while the 2007 flood data were used for model validation.

To assess the sensitivity of the different models to the model parameters, the Manning $n$ roughness coefficients for all the models were sampled uniformly from 0.02 to $0.08 \mathrm{~m}^{-1 / 3} \mathrm{~s}$ for the river channel, and between 0.03 and $0.10 \mathrm{~m}^{-1 / 3} \mathrm{~s}$ for the floodplain, by steps of $0.0025 \mathrm{~m}^{-1 / 3} \mathrm{~s}$. The performance of the hydraulic models in producing the observed water levels was assessed by means of the mean absolute error (MAE):

$\mathrm{MAE}=\frac{1}{T} \sum_{t=1}^{T}\left|O_{t}-S_{t}\right|$

where $T$ is the number of steps in time series, $O_{t}$ is the observed water level at time $t$, and $S_{t}$ is the simulated water level at time $t$.

\subsection{Quantifying the effect of the topographic data source on the water surface elevation and inundation area (sensitivity analysis)}

The effects of DEM source and spatial resolution were further investigated by examining the sensitivity of model results in terms of maximum water surface elevation (WSE), inundation area and floodplain boundaries. For this additional analysis, the model results obtained with the most accurate and precise DEM source (lidar at $1 \mathrm{~m}$ resolution) were used as a reference. For WSE analysis, each model was compared to the reference model ( $\mathrm{hr} \mathrm{L1}$, see Table 1) by means 
Table 3. Statistics of errors (m) of each DEMs with respect to the GPS control points.

\begin{tabular}{lrrr}
\hline $\begin{array}{l}\text { Model } \\
\text { name }\end{array}$ & $\begin{array}{r}\text { Min. } \\
\text { error (m) }\end{array}$ & $\begin{array}{r}\text { Max. } \\
\text { error (m) }\end{array}$ & RMSE (m) \\
\hline Jhr L1 & -0.59 & 1.00 & 0.58 \\
Jhr L2 & -0.64 & 1.38 & 0.58 \\
Jhr L20 & -0.83 & 1.83 & 0.68 \\
Jhr L30 & -0.93 & 3.98 & 0.79 \\
Jhr L90 & -5.46 & 3.73 & 1.27 \\
Jhr T20 & -15.38 & 10.55 & 4.66 \\
Jhr A30 & -33.37 & 7.58 & 7.01 \\
Jhr S90 & -3.59 & 4.32 & 6.47 \\
\hline
\end{tabular}
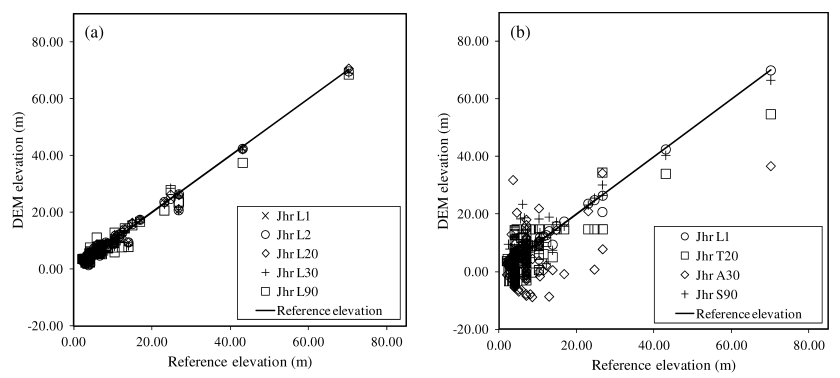

Figure 3. Comparison between GPS point elevations and elevations derived by the different DEMs: (a) lidar DEM at different resolution and (b) different sources of DEMs.

of the following measures:

$\mathrm{MAD}_{\mathrm{WSE}}=\frac{1}{x} \sum_{x=1}^{x}\left|\mathrm{WSE}_{\mathrm{Ref}}-\mathrm{WSE}_{\mathrm{DEM}}\right|$,

where WSE $E_{\text {Ref }}$ denotes the WSE simulated by the reference model (Jhr L1), WSEDEM the WSE estimated by the models based on DEMs of lower resolution or different source (Table 1), and $x$ corresponds to the total number of crosssections where models results where compared.

To analyse the sensitivity to different topographic input in terms of simulated flood extent, we used the following measure of fit:

$F(\%)=\frac{M_{1} \cap M_{2}}{M_{1} \cup M_{2}} \cdot 100$,

where $M_{1}$ and $M_{2}$ are the simulated and observed (i.e. simulated by the reference model) inundation areas, and $U$ and $\cap$ are the union and intersection GIS operations respectively. $F$ equal to $100 \%$ indicates that the two areas are completely coincidental.

\subsection{Uncertainty estimation - GLUE analysis}

In hydraulic modelling, multiple sources of uncertainty can emerge from several factors, such as model structure, topography and friction coefficients (Aronica et al., 2002; Trigg
Table 4. Reported vertical accuracies of SRTM data.

\begin{tabular}{|c|c|c|c|}
\hline Reference & accu & $\begin{array}{l}\text { verage } \\
\text { height } \\
\text { cy }(m)\end{array}$ & Continent \\
\hline Rabus et al. (2003) & \multirow{6}{*}{2.54} & 6.00 & European \\
\hline Sun et al. (2003) & & 11.20 & European \\
\hline $\begin{array}{l}\text { SRTM mission specification } \\
\text { (Rodríguez et al., 2005) }\end{array}$ & & 16.00 & Global \\
\hline Berry et al. (2007) & & 3.60 & Eurasia Global \\
\hline Farr et al. (2007) & & 6.20 & Eurasia \\
\hline Wang et al. (2011) & & 13.80 & Eurasia \\
\hline
\end{tabular}

et al., 2009; Brandimarte and Di Baldassarre, 2012; Dottori et al., 2013). A methodological approach to estimate the uncertainty is the generalized likelihood uncertainty estimation (GLUE) methodology (Beven and Binley, 1992), a variant of Monte Carlo simulation. Although some aspects of this methodology are criticized in several papers (e.g. Hunter et al., 2005; Mantovan and Todini, 2006; Montanari, 2005; Stedinger et al., 2008), it is still widely used in hydrological modelling because of its ease of implementation and a common-sense approach to use only a set of the "best" models for uncertainty analysis (e.g. Hunter et al., 2005; Shrestha et al., 2009; Vázquez et al., 2009; Krueger et al., 2010; Jung and Merwade, 2012; Brandimarte and Woldeyes, 2013).

According to the GLUE framework (Beven and Binley, 1992), each simulation, $i$, is associated with the (generalized) likelihood weight, $W_{i}$, ranging from 0 to 1 . The weight, $W_{i}$ is expressed as a function of the measure fit, $\varepsilon_{i}$, of the behavioural models:

$W_{i}=\frac{\varepsilon_{\max }-\varepsilon_{i}}{\varepsilon_{\max }-\varepsilon_{\min }}$,

where $\varepsilon_{\max }$ and $\varepsilon_{\min }$ are the maximum and minimum value of MAE of behavioural models. To identify the behaviour of the models, a threshold value (rejection criterion) has been set as follows:

1. simulations associated with MAE larger than $1.0 \mathrm{~m}$ and

2. Manning's $n$ roughness coefficient of the floodplain smaller than the Manning's $n$ roughness coefficient of the channel.

Then, the likelihood weights are the cumulative sum of 1 and the weighted 5th, 50th and 95th percentiles. The likelihood weights were calculated as follows:

$$
L_{i}=\frac{W_{i}}{\sum_{i=1}^{n} W_{i}} .
$$

For this study, the applications of uncertainty analysis considered only the parameter uncertainty and implemented for all DEMs. 

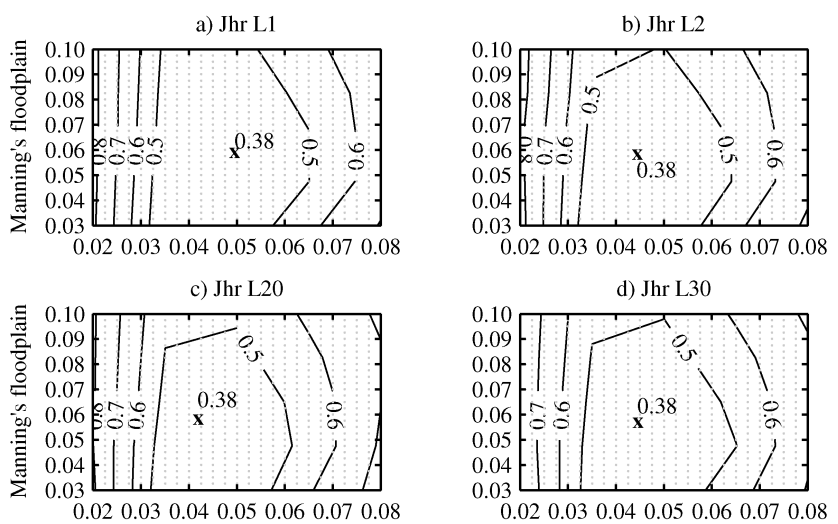

e) Jhr L90
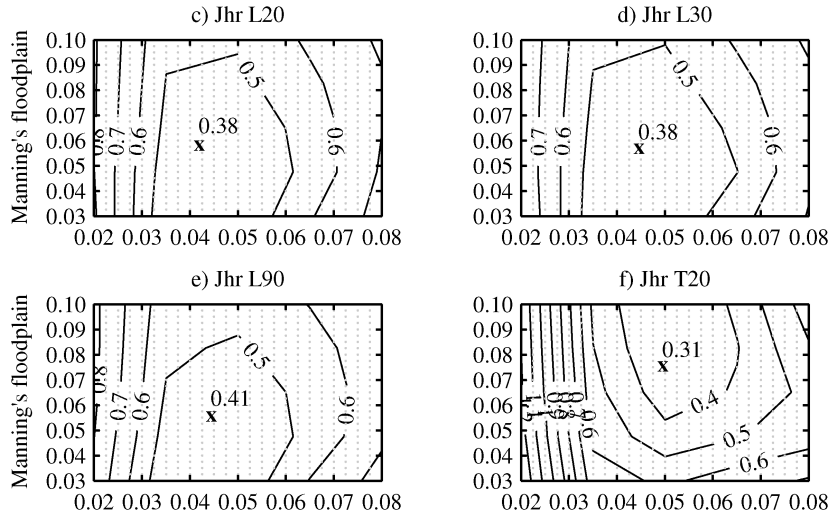

0.020 .030 .040 .050 .060 .070 .08
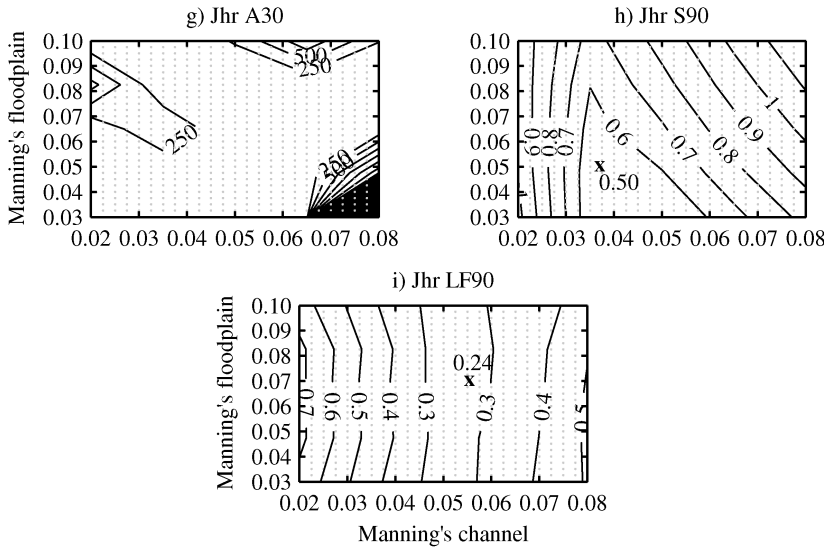

Figure 4. Model calibration: contour maps of MAE across the parameter space for (a-h) eight different 1-D models (HEC-RAS) and (i) for the 2-D model (LISFLOOD-FP).

Table 5. Model validation results.

\begin{tabular}{lcrr}
\hline $\begin{array}{l}\text { Model } \\
\text { name }\end{array}$ & \multicolumn{2}{c}{$\begin{array}{c}\text { Calibrated Manning's } n \\
\text { roughness coefficient }\end{array}$} & $\begin{array}{c}\text { MAE (m) } \\
\text { (validation) }\end{array}$ \\
\cline { 2 - 3 } & Channel & Floodplain & \\
\hline Jhr L1 & 0.0500 & 0.0575 & 0.40 \\
Jhr L2 & 0.0450 & 0.0575 & 0.38 \\
Jhr L20 & 0.0425 & 0.0575 & 0.37 \\
Jhr L30 & 0.0450 & 0.0575 & 0.38 \\
Jhr L90 & 0.0450 & 0.0550 & 0.39 \\
Jhr T20 & 0.0500 & 0.0750 & 0.60 \\
Jhr S90 & 0.0375 & 0.0500 & 0.60 \\
Jhr LF90 & 0.0550 & 0.0700 & 0.52 \\
\hline
\end{tabular}

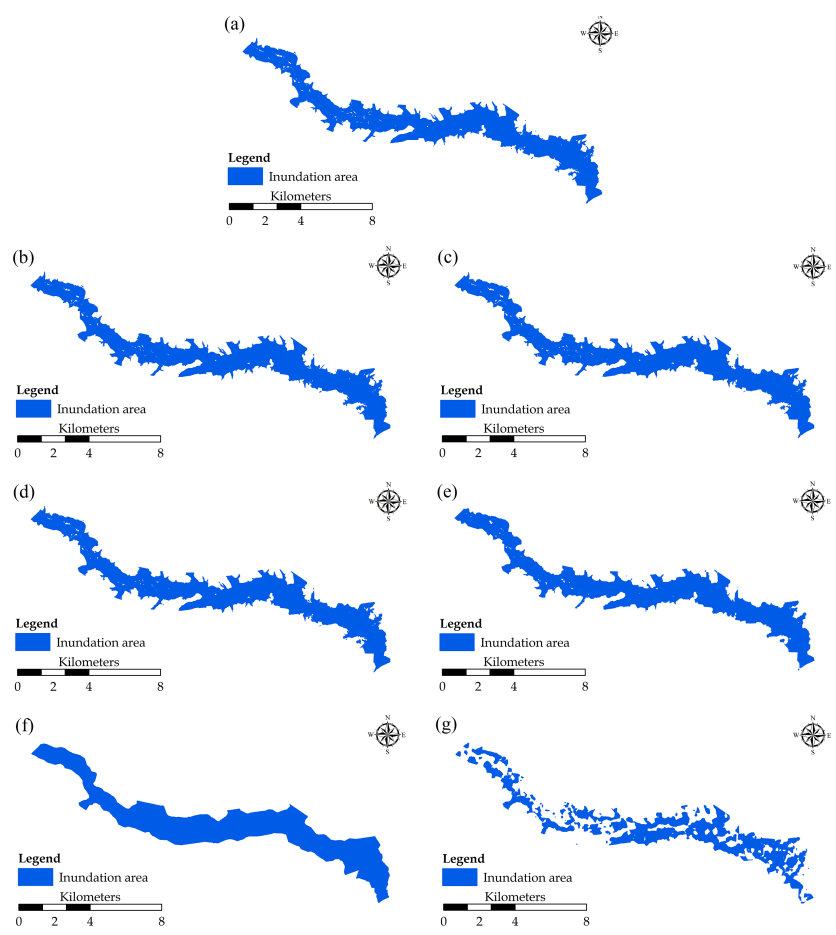

Figure 5. Effect of DEMs on Johor River. Inundation map resulting from (a) Jhr L1, (b) Jhr L2, (c) Jhr L20, (d) Jhr L30, (e) Jhr L90, (f) Jhr T20 and (g) Jhr S90.

\section{Results and discussion}

\subsection{Quality of DEMs compared with the reference points}

Table 3 shows the calculated statistical vertical errors for each different DEM for the same study area. As anticipated, lidar is not only the most precise DEM because of its highest resolution, but also the most accurate. The RMSE of each lidar DEM increased from $0.58 \mathrm{~m}$ (Jhr L1) to $1.27 \mathrm{~m}$ (Jhr L90) as the resolution of the DEMs reduced from $1 \mathrm{~m}$ (original resolution) to $90 \mathrm{~m}$.

Overall, the terrain is considered well defined under the lidar DEMs even though the calculated errors are higher compared to the vertical accuracy reported in product specification (around $0.15 \mathrm{~m}$ ). Figure 3 shows the distribution of each DEM compared to the GPS ground elevation.

Although lidar DEM gives the lowest error, it is useful to note that this type of DEM has a number of limitations as highlighted in the several papers (see Sun et al., 2003; Casas et al., 2006; Schumann et al., 2008):

1. it provides only discrete surface height samples and not continuous coverage,

2. its availability is very much limited by economic constraint, 
Table 6. Effects of DEMs (source and resolution) on HEC-RAS simulations.

\begin{tabular}{lrrrr}
\hline $\begin{array}{l}\text { Model } \\
\text { name }\end{array}$ & $\begin{array}{r}\text { Inundation } \\
\text { area }\left(\mathrm{km}^{2}\right)\end{array}$ & $\begin{array}{r}\text { Area } \\
\text { difference }(\%)\end{array}$ & $\begin{array}{r}F \\
(\%)\end{array}$ & $\begin{array}{r}F \\
(\%)^{+}\end{array}$ \\
\hline Jhr L1 & 25.86 & - & - & - \\
Jhr L2 & 25.78 & -0.3 & 96.6 & - \\
Jhr L20 & 25.96 & 0.4 & 92.9 & - \\
Jhr L30 & 26.18 & 1.2 & 92.2 & - \\
Jhr L90 & 25.84 & -0.1 & 89.4 & - \\
Jhr T20 & 29.23 & 13.0 & 73.7 & 74.2 \\
Jhr S90 & 16.58 & -35.9 & 48.9 & 49.6 \\
\hline
\end{tabular}

+ Overlap-fit percentage $\mathrm{F}(\%)$ of the floodplain inundated area with those from lidar DEMs of the same resolutions (Jhr L20, Jhr L90).

3. it is unable to capture the river bed elevations due to the fact the laser does not penetrate the water surface, and

4. it is incapable of penetrating the ground surface in densely vegetated areas especially for the tropical region.

The RMSE value of the other DEMs is $4.66 \mathrm{~m}$ for contour maps, $7.01 \mathrm{~m}$ for ASTER and $6.47 \mathrm{~m}$ for SRTM. It is also noticeable that the RMSE of the SRTM DEM for this particular study area is within the average height accuracy found in other SRTM literature - either global or at particular continent (see Table 4). Whatever the case, it is proven that this type of DEM gives an acceptable result when used in largescale flood modelling (e.g. Patro et al., 2009; Paiva et al., 2012; Yan et al., 2013).

Despite having the lowest vertical accuracies, the ASTER and contour DEMs are still widely used in the field of hydraulic flood research as they are globally available and free (e.g. Tarekegn et al., 2010; Wang et al., 2011; Gichamo et al., 2012). The differences in the vertical accuracies may be partly due to the lack of information in topographical flats areas such as floodplains. However, the further use of each DEM in this study is subject to its performance in the hydraulic flood modelling during the calibration and validation stages, which are described in the following section.

\subsection{Model calibration and validation}

Panels (a)-(h) of Fig. 4 show the model responses in terms of MAE provided by the eight HEC-RAS models in simulating the 2006 flood event. The models were built using the eight DEMs with different accuracy and precision (Table 2) as topographic input.

In general, all models (Fig. 4a-h) are seen to be more sensitive to the changing of Manning's $n$ roughness coefficient of main channel than the Manning's $n$ roughness coefficient of floodplain areas. The results of the calibration showed that the best-fit models based on lidar DEM with different resolutions (Jhr L2, Jhr L20, Jhr L30 and Jhr L90) generally gave good performances with only slight variations in
Table 7. Summary of mean absolute difference (MAD) in terms of water surface elevation simulated by the models.

\begin{tabular}{lr}
\hline Model name & MAD $_{\text {WSE }}(\mathrm{m})$ \\
\hline Jhr L1 & - \\
Jhr L2 & 0.06 \\
Jhr L20 & 0.05 \\
Jhr L30 & 0.05 \\
Jhr L90 & 0.08 \\
Jhr T20 & 1.12 \\
Jhr S90 & 0.76 \\
\hline
\end{tabular}

the MAE value from 0.38 to $0.41 \mathrm{~m}$. The optimum channel and floodplain Manning's $n$ roughness coefficient are centred on similar values at $n_{\text {channel }}=0.0425$ to 0.0500 and $n_{\text {floodplain }}=0.0575$ for Jhr L1, Jhr L2, Jhr L20, Jhr L30 and Jhr L90. The best-fit models based on topographic map and SRTM also performed well with MAE of 0.31 and $0.50 \mathrm{~m}$. On the other hand, ASTER-based model completely failed (the exceptionally high values of MAE in Fig. $4 \mathrm{~g}$ are due to model instabilities) and was therefore eliminated from further analysis.

Panel (i) of Fig. 4 shows the outcome of the additional experiment we carried out to test the appropriateness of selecting a 1-D model. In particular, a LISFLOOD-FP model was built using the lidar topography rescaled at $90 \mathrm{~m}$, called here Jhr LF90. The specific topographic input was chosen as a trade-off between computational times and the need for an as-accurate-as-possible DEM for a proper comparison between 1-D and 2-D modelling. By comparing the calibration results of the LISFLOOD-FP model (Fig. 4i) to the corresponding (i.e. using the same topography) ones of the HECRAS model (Fig. 4e), one can observe that differences are not significant. Lastly, Fig. 4 i shows that LISFLOOD-FP is also more sensitive to the main channel roughness coefficient than to the floodplain one.

The best-fit models, using the optimum Manning $n$ roughness coefficients (Table 5), were then used to simulate the January 2007 flood event for model validation. This was carried out for all models except the ASTER-based model due to its poor performance (see Fig. $4 \mathrm{~g}$ ). Table 5 presents the MAE of each model obtained during model validation. It is noted that the MAE values for all lidar-based models (first five rows) with different resolutions remained almost the same with the difference within $+0.03 \mathrm{~m}$. The MAE values for the models based on topographic contour maps and SRTM DEM both provide MAE of $0.60 \mathrm{~m}$.

The model validation exercise also supports the use of 1-D hydraulic models for this river reach. In particular, Table 5 shows that the LISFLOOD-FP model (Jhr LF90) provided a MAE of $0.52 \mathrm{~m}$, while the corresponding HEC-RAS model (Jhr L90) provided a MAE of $0.39 \mathrm{~m}$. Thus, the 1-D model performed even (slightly) better than the 2-D model. 

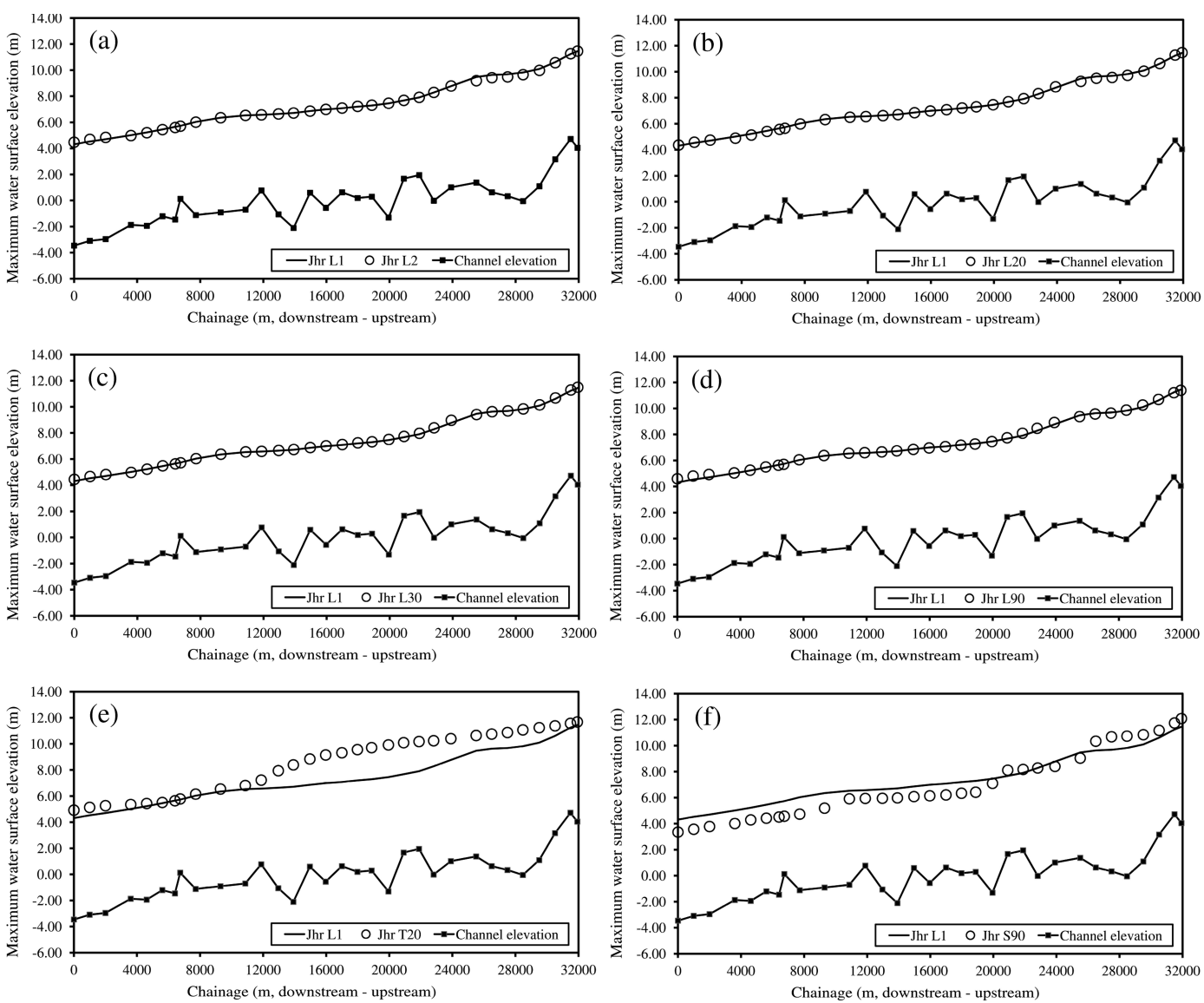

Figure 6. Maximum water surface elevation along the Johor River for the six hydraulic models compared to that simulated by the reference model.

The results of this first analysis suggest that the reduction in the resolution of lidar DEMs (from 1 to $90 \mathrm{~m}$ ) does not significantly affect the model performance. However, the use of topographic contour maps (Jhr T20) and SRTM (Jhr S90) DEMs as geometric input to the hydraulic model produces a slight increase of model errors. For instance, Jhr L90 and $\mathrm{Jhr}$ S90 have the same resolution $(90 \mathrm{~m})$, but the different accuracy results in increased (tough not remarkably) errors in model validation (from 0.39 to $0.60 \mathrm{~m}$ ). This limited degradation of model performance (Table 5), in spite of the much lower accuracy of topographic input (Table 2), can be attributed to the fact that models are compared to water levels observed in two cross-sections. A spatially distributed analysis (comparing the simulated flood extent and flood water profile along the river) might show more significant differences (see Sect. 4.3).

\subsection{Quantifying the effect of the topographic data source on the water surface elevation and inundation area on 1-D model}

\subsubsection{Inundation area (sensitivity analysis)}

This section reports an additional analysis aiming to better explore the sensitivity of model results to different topographic data (see Sect. 3.3). Figure 5 shows the simulated flood extent maps obtained from the seven different topographic input data. The floodplain areas simulated by the five lidar-based models (Jhr L1, Jhr L2, Jhr L20, Jhr L30 and Jhr L90) are very similar. In contrast, the floodplain areas simulated by the models based on topographic contour maps (Jhr T20) and SRTM DEM (Jhr S90) are substantially different (see Fig. 5 and Table 6).

Table 6 shows the comparison between the different models in terms of simulating flood extent. The aforementioned measure of fit $F$ was found to decrease for both decreasing resolution and lowering accuracy. This sensitivity analysis also shows that the results of flood inundation models are more affected by the accuracy of the DEM used as topographic input than its resolution. 

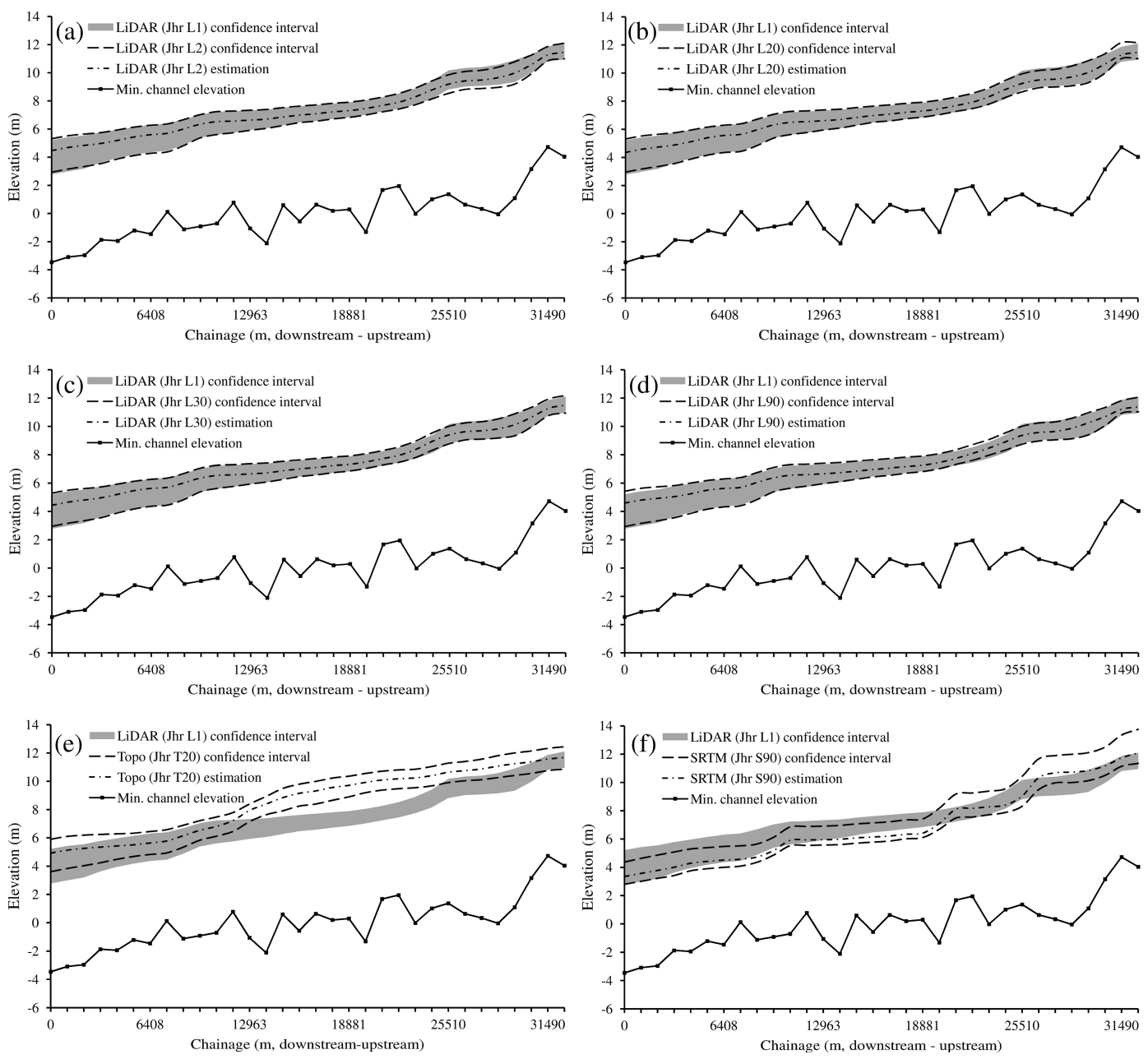

Figure 7. Comparison of uncertainty bounds (5th, 50th and 95 th percentiles by considering parameter uncertainty only) between the reference model and the other models. The reference model uncertainty bounds are shown as grey areas, while the uncertainty bounds of the other six models are shown as dashed lines.

\subsubsection{Water surface elevation}

Figure 6 compares the flood water profiles simulated by the reference model (Jhr L1) with the flood water profiles (WSE) obtained from the other six models (Jhr L2, Jhr L20, Jhr L30, Jhr L90, Jhr T20 and Jhr S90). All these flood water profiles were obtained by simulating the 2007 flood event. Despite having different resolutions, the flood water profiles simulated from all lidar-based models portray similar flood water profiles to the reference model (see Fig. 6a to d). This is consistent with the findings about the inundation area (Fig. 5), whereas flood water profiles simulated by the models based on topographic contour maps and SRTM DEMs (see Fig. 6e and $\mathrm{f}$ ) are rather different.

The discrepancies between the reference model (Jhr L1) and the other models as shown in Fig. 6 are quantified in terms of mean absolute difference (MAD). This shows that the re-sampled lidar data (Jhr L2, Jhr L20, Jhr L30 and Jhr L90) all have a low MAD: between 0.05 to $0.08 \mathrm{~m}$. Higher discrepancies are found with the models based on SRTM DEM $(0.76 \mathrm{~m})$ and contour maps $(1.12 \mathrm{~m})$. The great differences obtained using the topographic contour maps may be partly due to the way that the DEM height is sampled. For instance, the contour DEMs in this study were based on topographic contours at $20 \mathrm{~m}$ intervals and required an interpolation technique to generate a DEM. Table 7 shows the MAD in terms of water surface elevation simulated by the models.

\subsubsection{Uncertainty in flood profiles obtained from different DEMs by considering parameter uncertainty}

To better interpret the differences that have emerged in comparing the results of models based on different topographic data, we carried out a set of numerical experiments to explore the uncertainty in model parameters. As mentioned, we varied Manning's $n$ roughness coefficient between 0.02 and $0.08 \mathrm{~m}^{-1 / 3} \mathrm{~s}$ for the river channel, and from 0.03 to 
$0.10 \mathrm{~m}^{-1 / 3} \mathrm{~s}$ for the floodplain, in steps of $0.0025 \mathrm{~m}^{-1 / 3} \mathrm{~s}$. Then a number of simulations were rejected as described in Sect. 3.4. Figure 7 shows the uncertainty bounds for the different models. The width of these uncertainty bounds was found to be between 1.5 and $1.6 \mathrm{~m}$ for all models (only parameter uncertainty is considered here). Nevertheless, the model based on contour maps led to significant differences from the lidar-based model, even when the uncertainty induced by model parameters is explicitly accounted for (see Fig. 7e).

\section{Conclusions}

This study assessed how different DEMs (derived by various sources of topographic information or diverse resolutions) affect the output of hydraulic modelling. A reach of the Johor River, Malaysia, was used as the test site. The study was performed using a 1-D model (HEC-RAS), which was found to perform as well as a 2-D model (LISFLOOD-FP) in this case study. The sources of DEMs were lidar at $1 \mathrm{~m}$ resolution, topographic contour maps at $20 \mathrm{~m}$ resolution, ASTER data at $30 \mathrm{~m}$ resolution, and SRTM data at $90 \mathrm{~m}$ resolution. The lidar DEM was also re-sampled from its original resolution data set to 2, 20, 30 and $90 \mathrm{~m}$ cell size. Different models were built by using them as geometric input data.

The performance of the five lidar-based models (characterized by different resolutions ranging from 1 to $90 \mathrm{~m}$; see Table 5) did not show significant differences - neither in the exercise of independent calibration and validation based on water level observations in an internal cross-section, nor in the sensitivity analysis of simulated flood profiles and inundation areas. Another striking result of our study is that the model based on ASTER data completely failed because of major inaccuracies of the DEM.

In contrast, the models based on SRTM data and topographic contour maps did relatively well in the validation exercise as they provided a mean absolute error of $0.6 \mathrm{~m}$, which is only slightly higher than the ones obtained with lidar-based models (all around $0.4 \mathrm{~m}$ ). However, this outcome could be attributed to the fact that validation could only be performed by using the water level observed in a two internal crosssections. As a matter of fact, higher discrepancies emerged when lidar-based models were compared to the models based on SRTM data or topographic contour maps in terms of inundation areas or flood water profiles. These differences were found to be relevant even when parameter uncertainty was accounted for.

The study also showed that, to support flood inundation models, the quality and accuracy of the DEM is more relevant than the resolution and precision of the DEM. For instance, the model based on the $90 \mathrm{~m}$ DEM obtained by re-sampling the lidar data performed better than the model based on the $90 \mathrm{~m}$ DEM obtained from SRTM data. These outcomes are unavoidably associated with the specific test site, but the methodology proposed here can allow a comprehensive assessment of the impact of diverse topographic data on hydraulic modelling of floods for different rivers around the world.

Acknowledgements. The authors would like to thank to the Department of Irrigation and Drainage, Malaysia (DID) for providing useful input data used in this study. We also acknowledge the Public Service Department, Malaysia for providing a $\mathrm{PhD}$ Fellowship funding and study leave for the first author. We thank the Editor and the two anonymous reviewers as well as Fiona, Nagendra, Micah and Yan for their constructive comments that helped to improve the manuscript.

Edited by: H. Cloke

\section{References}

Aronica, G., Bates, P. D., and Horritt, M. S.: Assessing the uncertainty in distributed model predictions using observed binary pattern information within GLUE, Hydrol. Process., 16, 2001-2016, doi:10.1002/hyp.398, 2002.

Bates, P. D., Marks, K. J., and Horritt, M. S.: Optimal use of highresolution topographic data in flood inundation models, Hydrol. Process., 17, 5237-5257, 2003.

Bates, P. D., Horritt, M. S., and Fewtrell, T. J.: A simple inertial formulation of the shallow water equations for efficient twodimensional flood inundation modelling, J. Hydrol., 387, 33-45, doi:10.1016/j.jhydrol.2010.03.027, 2010.

Bates, P. D.: Integrating remote sensing data with flood inundation models: how far have we got?, Hydrol. Process., 26, 2515-2521, doi:10.1002/hyp.9374, 2012.

Berry, P. A. M., Garlick, J. D., and Smith, R. G.: Near-global validation of the SRTM DEM using satellite radar altimetry, Remote Sens. Environ., 106, 17-27, doi:10.1016/j.rse.2006.07.011, 2007.

Beven, K. and Binley, A.: The future of distributed models - model calibration and uncertainty prediction, Hydrol. Process., 6, 279298, doi:10.1002/hyp.3360060305, 1992.

Brandimarte, L. and Di Baldassarre, G.: Uncertainty in design flood profiles derived by hydraulic modelling, Hydrol. Res., 43, 753761, doi:10.2166/nh.2011.086, 2012.

Brandimarte, L. and Woldeyes, M. K.: Uncertainty in the estimation of backwater effects at bridge crossings, Hydrol. Process., 27, 1292-1300, doi:10.1002/hyp.9350, 2013.

Casas, A., Benito, G., Thorndycraft, V. R., and Rico, M.: The topographic data source of digital terrain models as a key element in the accuracy of hydraulic flood modelling, Earth Surf. Process Landforms, 31, 444-456, doi:10.1002/esp.1278, 2006.

Castellarin, A., Di Baldassarre, G., Bates, P. D., and Brath, A.: Optimal cross-section spacing in Preissmann scheme 1-D hydrodynamic models, J. Hydraul. Eng.-ASCE, 135, 96-105, doi:10.1061/(ASCE)0733-9429(2009)135:2(96), 2009.

Cobby, D. M. and Mason, D. C.: Image processing of airborne scanning laser altimetry for improved river flood modelling, ISPRS J. Photogramm. Remote Sens., 56, 121-138, 1999. 
Cook, A. and Merwade, V.: Effect of topographic data, geometric configuration and modeling approach on flood inundation mapping, J. Hydrol., 377, 131-142, 2009.

Coulthard, T. J., Neal, J. C., Bates, P. D., Ramirez, J., de Almeida, G. A. M., and Hancock, G. R.: Integrating the LISFLOOD-FP 2D hydrodynamic model with the CAESAR model: implications for modelling landscape evolution, Earth Surf. Process. Landforms, 38, 1897-1906, doi:10.1002/esp.3478, 2013.

Department of Irrigation and Drainage, Malaysia (DID): Master plan study on flood mitigation for Johor River basin, Malaysia, 2009.

Di Baldassarre, G., Schumann, G., and Bates, P. D.: A technique for the calibration of hydraulic models using uncertain satellite observations of flood extent, J. Hydrol., 367, 276-282, 2009.

Di Baldassarre, G., Schumann, G., Bates, P. D., Freer, J. E., and Beven, K. J.: Floodplain mapping: a critical discussion on deterministic and probabilistic approaches, Hydrolog. Sci. J., 55, 364-376, 2010.

Di Baldassarre, G. and Uhlenbrook, S.: Is the current flood of data enough? A treatise on research needs for the improvement of flood modelling, Hydrol. Process., 26, 153-158, doi:10.1002/hyp.8226, 2012.

Dottori, F., Di Baldassarre, G., and Todini, E.: Detailed data is welcome, but with a pinch of salt: Accuracy, precision, and uncertainty in flood inundation modelling, Water Resour. Res., 49, 6079-6085, doi:10.1002/wrcr.20406, 2013.

Farr, T. G., Rosen, P. A., Caro, E., Crippen, R., Duren, R., Hensley, S., Kobrick, M., Paller, M., Rodriguez, E., Roth, L., Seal, D., Shaffer, S., Shimada, J., Umland, J., Werner, M., Oskin, M., Burbank, D., and Alsdorf, D.: The shuttle radar topography mission, Rev. Geophys., 45, RG2004, doi:10.1029/2005RG000183, 2007.

Gichamo, T. Z., Popescu, I., Jonoski, A., and Solomatine, D.: River cross-section extraction from the ASTER global DEM for flood modelling, Environ. Modell. Softw., 31, 37-46, doi:10.1016/j.envsoft.2011.12.003, 2012.

Horrit, M. S. and Bates, P. D.: Effects of spatial resolution on a raster based model of flood flow, J. Hydrol., 253, 239-249, 2001.

Horrit, M. S. and Bates, P. D.: Evaluation of 1-D and 2-D models for predicting river flood inundation, J. Hydrol., 180, 87-99, 2002.

Hunter, N. M., Bates, P. D., Horritt, M. S., De Roo, A. P. J., and Werner, M. G. F.: Utility of different data types for calibrating flood inundation models within a GLUE framework, Hydrol. Earth Syst. Sci., 9, 412-430, doi:10.5194/hess-9-412-2005, 2005.

Hunter, N. M., Bates, P. D., Horritt, M. S., and Wilson, M. D.: Improved simulation of flood flows using storage cell models, P. I. Civil Eng.-Wat. M., 159, 9-18, 2006.

Jung, Y. and Merwade, V.: Uncertainty quantification in flood inundation mapping using generalized likelihood uncertainty estimate and sensitivity analysis, J. Hydrol. Eng., 17, 507-520, 2012.

Krueger, T., Freer, J., Quinton, J. N., Macleod, C. J. A., Bilotta, G. S., Brazier, R. E., Butler, P., and Haygarth, P. M.: Ensemble evaluation of hydrological model hypotheses, Water Resour. Res., 46, W07516, doi:10.1029/2009WR007845, 2010.

Mantovan, P. and Todini, E.: Hydrological forecasting uncertainty assessment: incoherence of the GLUE methodology, J. Hydrol., 330, 368-381, doi:10.1016/j.jhydrol.2006.04.046, 2006.
Marks, K. and Bates, P. D.: Integration of high resolution topographic data with floodplain flow models, Hydrol. Process., 14, 2109-2122, 2000.

Merwade, V., Olivera, F., Arabi, M., and Edleman, S.: Uncertainty in flood inundation mapping: current issues and future directions, J. Hydrol. Eng., 13, 608-620, 2008.

Montanari, A.: Large sample behaviors of the generalized likelihood uncertainty estimation (GLUE) in assessing the uncertainty of rainfall-runoff simulations, Water Resour. Res., 41, W08406, doi:10.1029/2004WR003826, 2005.

Moya Quiroga, V., Popescu, I., Solomatine, D. P., and Bociort, L.: Cloud and cluster computing in uncertainty analysis of integrated flood models, J. Hydroinf., 15, 55-69, doi:10.2166/hydro.2012.017, 2013.

Neal, J., Schumann, G., and Bates, P.: A subgrid channel model for simulating river hydraulics and floodplain inundation over large and data sparse areas, Water Resour. Res., 48, W11506, doi:10.1029/2012WR012514, 2012.

Paiva, R. C. D., Collischonn, E., and Tucci, C. E. M.: Large scale hydrologic and hydrodynamic modeling using limited data and a GIS based approach, J. Hydrol., 406, 170-181, doi:10.1016/j.jhydrol.2011.06.007, 2011.

Pappenberger, F., Beven, K. J., Horritt, M., and Blazkova, S.: Uncertainty in the calibration of effective roughness parameters in HEC-RAS using inundation and downstream level observations, J. Hydrol., 302, 46-69, 2005.

Patro, S., Chatterjee, C., Singh, R., and Raghuwanshi, N. S.: Hydrodynamic modelling of a large flood-prone system in India with limited data, Hydrol. Process., 23, 2774-2791, doi:10.1002/hyp.7375, 2009.

Rabus, B., Eineder, M., Roth, A., and Bamler, R.: The shuttle radar topography mission - a new class of digital elevation models acquired by spaceborne radar, ISPRS J. Photogramm. Remote Sens., 57, 241-262. doi:10.1016/S0924-2716(02)00124-7, 2003.

Rodríguez, E., Morris, C. S., Belz, J. E., Chapin, E. C., Martin, J. M., Daffer, W., and Hensley, S.: An assessment of the SRTM topographic products, Technical Report JPL D-31639, Jet Propulsion Laboratory, Pasadena, California, 143 pp., http: //www2.jplnasa.gov/srtm/srtmBibliography.html (last access: 16 December 2013), 2005.

Schumann, G., Matgen, P., Cutler, M. E. J., Black, A., Hoffmann, L., and Pfister, L.: Comparison of remotely sensed water stages from LiDAR, topographic contours and SRTM, ISPRS J. Photogramm. Remote Sens., 63, 283-296, 2008.

Schumann, G., Di Baldassarre, G., Alsdorf, D., and Bates, P. D.: Near real-time flood wave approximation on large rivers from space: application to the River Po, Northern Italy, Water Resour. Res., 46, W05601, doi:10.1029/2008WR007672, 2010.

Shrestha, D. L., Kayastha, N., and Solomatine, D. P.: A novel approach to parameter uncertainty analysis of hydrological models using neural networks, Hydrol. Earth Syst. Sci., 13, 1235-1248, doi:10.5194/hess-13-1235-2009, 2009.

Stedinger, J. R., Vogel, R. M., Lee, S. U., and Batchelder, R.: Appraisal of the generalized likelihood uncertainty estimation (GLUE) method, Water Resour. Res., 44, W00B06, doi:10.1029/2008WR006822, 2008.

Sun, G., Ranson, K. J., Kharuk, V. I., and Kovacs, K.: Validation of surface height from shuttle radar topography mission us- 
ing shuttle laser altimetry, Remote Sens. Environ., 88, 401-411. doi:10.1016/j.rse.2003.09.001, 2003.

Tarekegn, T. H., Haile, A. T., Rientjes, T., Reggiani, P., and Alkema, D.: Assessment of an ASTER generated DEM for 2D flood modelling, Int. J. Appl. Earth Obs. Geoinf., 12, 457-465. doi:10.1016/j.jag.2010.05.007, 2010.

Trigg, M. A., Wilson, M. D., Bates, P. D., Horritt, M. S., Alsdorf, D. E., Forsberg, B. R., and Vega, M. C.: Amazon flood wave hydraulics, J. Hydrol., 374, 92-105, 2009.

USACE: HEC-RAS River Analysis System User's Manual. Version 4.1, Hydrologic Engineering Center, Davis, California, 2010.

Vázquez, R. F., Beven, K., and Feyen, J.: GLUE based assessment on the overall predictions of a MIKE SHE application, Water Resour. Res., 23, 1325-1349, doi:10.1007/s11269-008-9329-6, 2009.
Wang, W., Yang, X., and Yao, T.: Evaluation of ASTER GDEM and SRTM and their suitability in hydraulic modelling of a glacial lake outburst flood in southeast Tibet, Hydrol. Process., 26, 213 225, doi:10.1002/hyp.8127, 2011.

Werner, M. G. F.: Impact of grid size in GIS based flood extent mapping using a 1-D flow model, Phys. Chem. Earth Pt. B, 26, 517-522, 2001.

Wilson, M. D. and Atkinson, P. M.: The use of elevation data in flood inundation modelling: a comparison of ERS interferometric SAR and combined contour and differential GPS data, Intl. J. River Basin Management, 3, 3-20, doi:10.1080/15715124.2005.9635241, 2005.

Yan, K., Di Baldassarre, G., and Solomatine D. P.: Exploring the potential of SRTM topographic data for flood inundation modelling under uncertainty, J. Hydroinf., 15, 849-861, doi:10.2166/hydro.2013.137, 2013. 